\title{
On the "Generality" of the General Theory. Or Why Keynes Lost His Battle and What to Do to Re-win It Again
}

\author{
Teodoro Dario Togati \\ University of Turin, Turin, Italy
}

\begin{abstract}
The paper emphasizes the true "generality" of the General Theory (GT) in the face of the dominant view, according to which Keynes's theory is captured by "Keynesian outcomes" in axiomatic general equilibrium models due to market imperfections. However, it argues that the advocates of generality must make a serious effort to re-conceptualize the GT in a very broad perspective. One must understand both its limitations and why the generality debate after the GT has failed to reconsider it in a proper way and what to do to restore Keynes's generality claim in the present context. This paper's contribution is twofold. The first is to make a distinction between three different dimensions of the generality issue and suggest that Keynes failed to grasp their full significance because he was facing the Marshallian orthodoxy, rather than general equilibrium. The second contribution is to suggest that one way to restore Keynes's generality claim is to stress that he belongs to an alternative paradigm that has several features in common with contemporary modernist revolution and with Einstein's relativity theory in particular.
\end{abstract}

Keywords: conventions, stability, macroeconomics, Keynesianism

\section{Introduction}

There is no doubting the revolutionary character of the General Theory (GT). However, the failure of Keynes's claim about the generality of his main contribution is also indisputable. Even the Great Recession has not led macroeconomists to call into question the dominant view, according to which the GT is nothing but a particular case in standard general equilibrium macro, due to market imperfections and price rigidities.

There is no doubting that some internal limitations of the GT also account for this state of affairs. In particular, this paper holds that its cardinal sin is what Leontief, in his analysis of the GT, labeled as "implicit theorizing” (e.g., Leontief, 1937, for a similar claim concerning epistemology and methodology, see Dow, 2013, for analysis of this issue Togati, 2019). ${ }^{1}$

Teodoro Dario Togati, Ph.D., professor, School of Management and Economics, University of Turin, Turin, Italy.

Correspondence concerning this article should be addressed to Teodoro Dario Togati, Dipartimento di Scienze Economico-Sociali e Matematico-Statistiche, School of Management and Economics, University of Turin, Corso Unione Sovietica, 218 bis, 10134, Torino (Italy).

1 “Keynes himself made only limited explicit reference to epistemological and methodological issues in his economic writing. Indeed it has been the teasing out of the epistemology and methodology implicit in Keynes's economics that represented an exciting challenge for post-Keynesian methodologists. But Keynes could perhaps have prevented some of the confusion in interpreting the General Theory if he had been more explicit in specifying why he constructed it the way he did. And indeed it was the (mis) interpretations on the part of orthodox economists in the 1940s and 1950s that led to Keynes's ideas being subsumed in the neoclassical synthesis" (Dow, 2013, p. 80). 
Strictly speaking, with the benefit of hindsight, we can regard Keynes's implicit theorizing as being "forced", that is an almost inevitable result of the fact that he was facing the Marshalllian orthodoxy (which he shared to a large extent), rather than general equilibrium.

This paper's first contribution is to focus on the consequences of Keynes's implicit theorizing — which have been relatively neglected in the post-Keynesian literature-over three different dimensions of generality: extensive, substantive, and policy. Keynes's defeat in the generality battle is to a large extent due to the fact that he focused more on introducing new variables into a framework derived from classical theory (extensive generality) rather than in providing an explanation of these new variables (substantive generality) and/or constructing a full blown alternative paradigm covering both short and long period analysis (generality in policy terms).

This paper's second contribution is to show that a full articulated and internally consistent Keynesian "paradigm"-based on a distinction between three key features, namely "postulates", "simplifying assumptions", and "heuristics"— can be built by stressing the links between Keynes's revolution and one of the key contemporary revolutions, namely Einstein's relativity theory.

The paper is structured as follows. The first section deals with the limitations of Keynes's generality stance. The second section briefly examines the debate over generality in the post-Keynesian literature. In the end, the third section focuses on the definition of Keynes's paradigm in the light of the Keynes/Einstein analogy.

\section{The Limitations of Keynes}

These limits can be more easily understood if we make a distinction between three different dimensions of the generality issue: extensive, intensive, and policy.

\section{Extensive Generality}

As already noted, Keynes's implicit theorizing is the almost inevitable result of the fact that he was facing the Marshalllian paradigm—in the shape of Pigou's classical model—whose presuppositions—such as organic interdependence view, broad view of rationality and competition, reference to real world conditions in which people rely on conventions - he shared to a large extent. Clearly, he could not be prepared to demarcate his approach from general equilibrium built on quite different presuppositions, such as atomistic and axiomatic foundations, which was simply not there (see Togati, 2019).

In particular, Keynes built his approach on the same "quasi-naturalistic" grounds as Marshall, i.e., his aggregate propensities referring to psychological or generic features of human behaviour that were neither atomistic (and thus cannot be treated as if they were natural data, like preferences in standard theory) nor fully historical.

For this reason, he regarded generality mainly as a matter of "extension” of Marshall's partial equilibrium approach to the aggregate level, as shown for example by his AD/AS apparatus (seen as generalization of Pigou's classical model) and his emphasis on the causal role of money and expectations.

Now, while certainly successful in the face of Pigou, this extensive strategy has proved insufficient in the face general equilibrium. Suffice it to note that, unlike the Marshallian tradition, the latter is based on a high degree of formalization that allows an add-on strategy capable of achieving the formal inclusion of all new Keynesian variables in models based on individual rationality. 
In particular, as is well known, throughout the years, general equilibrium has managed to absorb many of the Keynesian novelties through a linguistic reformulation carried out on the grounds of the axioms of individual rationality replacing Keynes's "quasi-naturalistic" foundations, with obvious loss of meaning: uncertainty has been reduced to probabilistic calculus, money to "confetti", expectations to rational expectations, involuntary unemployment to the natural rate of unemployment, and so on (e.g., Togati, 2018).

\section{Substantive Generality}

But this is not all. What also accounts for the current state of affairs is that, as a result of his extensive strategy, Keynes relatively neglected two other dimensions of generality. The first is the "substantive" one, according to which a more general theory is one that improves or provides better accounts or explanations than the alternative approaches.

Today this relative neglect appears a very serious limitation since it is precisely on this substantive ground that general equilibrium actually fails. Indeed, many authors stress the limitations of its add-on strategy: formal inclusion does not correspond to explanatory ability (see e.g., Greenspan recently) ${ }^{2}$. Key variables like money and expectations are present in standard models but are not accounted for in terms of "first principles". Moreover, in standard macro such variables fail to play a causal role and/or affect equilibrium in view of the internal stability assumption.

On the contrary, the Keynesian approach has still a relatively high unexplored potential in this respect. Keynes regarded money and expectations as primary causal variables capable of affecting real equilibrium thus opening the way to an endogenous account of stability. However, one limitation of his contribution is that he did not clarify the ultimate explanatory factors that justify such casual role and endogenous account.

Indeed, one of the aspects of Keynes's forced implicit theorizing is that he failed to clarify his postulates in a manner paralleling general equilibrium. While the latter relies on the axioms of individual rationality, the constructive method and equilibrium (see e.g., Togati, 2019), it is not at all clear what are the corresponding postulates of the GT; in particular, it is not clear the status of Keynes's "quasi naturalistic" approach: to what extent can his aggregate propensities be reduced to individual rationality? Are they a postulate or simplifying assumptions? The answers to the questions confirm the limits of the GT.

Suffice it to note that if the "quasi-naturalistic" features were a postulate the GT would not provide a full alternative to standard approach at the explanatory level. It could still be regarded as being consistent with one postulate of standard theory, namely individual rationality as shown for example by game theory and thus cannot really account for endogeneity. For good or bad, the psychological laws are exogenous to the economy (it is not important per se whether these psychological determinants are consistent with maximization—or even rationality or not-it is more important to note that the individual remains the ultimate explanatory factor).

On the other hand, if such features turned out to be just a simplifying assumption, we would still need to single out the postulates of the GT in order to assert its alternative character and clarify the foundations of Keynes's endogenous instability view.

\section{Generality in Terms of Policy}

The other dimension of generality that Keynes neglected is the "policy" dimension, according to which a

\footnotetext{
2 “Current practice is to introduce ... 'animal spirits' ... through 'add factors'. That is, we arbitrarily change the outcome of our model's equations. Add-factoring, however, is an implicit recognition that models ... are structurally deficient; it does not sufficiently address the problem of the missing variable” (Greenspan, 2008, my italics).
} 
theory is more general than another if it represents a better anchor for agents' expectations in the real world, that is if it is able to act as a "popular" model to steer policymakers. This ability strictly depends upon "internal consistency": A general theory must produce a consistent story about the working of the economy as a whole, both at a moment of time and in dynamic terms, stressing its adjustment mechanisms and so on; that is, it must provide a full-blown paradigm.

Now while making a heroic effort to build macro on the grounds of his notion of equilibrium at point in time, Keynes was not prepared to provide a full-blown paradigm. Facing the Marshallian tradition which was not formalized and internally consistent, for him it was sufficient to be relatively vague about the linkages between short and long period analysis. However, this approach is not sufficient today in the face of general equilibrium.

Despite its explanatory failure, standard macro is successful in pragmatic terms: it is widely regarded as the "true model" of the economy shaping agents' expectations, in line with the rational expectations assumption. It is the product of a full-blown paradigm meeting today's prevailing methodological standards, such as formalization and internal consistency. In particular, it appears as the true model of the economy because it covers both fluctuations and growth on the grounds of same apparatus, thus restoring primacy of the long-run growth as intellectual reference point for describing the normal working of the economy.

Now it is beyond dispute that ever since Hicks's 1937 essay started to apply the general equilibrium logic to macro, Keynes's theory, despite its substantial policy success, ${ }^{3}$ has been instead increasingly denied a truly autonomous theoretical status in modern macroeconomics; it is considered as being nothing more than a set of practical "short-cuts" (to rely upon in case of deep recessions) or ad hoc assumptions, a kind of intellectual "witch’s brew" (Blanchard, 2000) with respect to a "highbrow" theoretical approach, such as general equilibrium.

This result should not be surprising. As it stands, the GT does not work as alternative true model or competing policy paradigm, because it fails to talk about the "normal" times due to its lack of internal articulation. For example, in the book there is no distinction between fundamental assumptions or postulates and simplifications, as shown by endless controversies over the role of fundamental concepts such as equilibrium, money, history, or institutions in the GT. This book seems to be confined to instantaneous equilibrium where all the fundamental data are given. However, this leaves Keynes's model in uneasy waters. Suffice it to note that, unlike the parameters of standard theory which can profitably be taken as given in the light of its internal stability assumption, Keynes's data instead should not be treated in this way. In the light of his internal instability assumption, he should have given clues on how such data were likely to change in given historical contexts.

\section{The Limitations of the Debate Over Generality}

It can be argued that the generality debate after the publication of the GT has been quite deceiving. By and large, it has been unable to overcome Keynes's key limitations, as shown by the fact that even post-Keynesians (PK) have failed to converge on a unifying interpretation concerning the generality issue:

1. Many PK do not see problems in Keynes's generality stance and simply suggest that his critique of standard theory is right (e.g., Gerrard, 1995);

\footnotetext{
${ }^{3}$ Indeed, it can be argued that it is only because of the Keynesian instincts of policymakers that the repeat of the Great Depression has been avoided. More in general, from the policy standpoint, the Keynesian insight that the macroeconomy needs to be stabilized has won in that ever since the 1930s the G/GDP ratio has increased dramatically in all countries.
} 
2. Others call into question Keynes's generality claim itself because he neglects history and institutional detail (e.g., Hodgson, 2001, for analysis of this issue see Togati, 2020);

3. Only a few raise the issue of Keynes's postulates. Davidson (2003) for example suggests that they have to do with the properties of money, emphasized by Keynes in Chapter 17 of the GT.

\section{How to Restore Generality of the GT}

I make two basic claims about how to restore Keynes's generality claim. The first is that the full statement of Keynes's paradigm - making explicit what is at best only implicit in the GT-is needed to restore its generality in all dimensions.

Secondly, I argue that to make an intellectual and policy impact in the present context this paradigm should meet the methodological criteria that are shared today by a large part of the community of scholars, such as internal consistency and formalization. This does not mean that the GT should be dealt with in terms of the same deductivist methods underlying the dominant general equilibrium macro. These methods are just one particular way of meeting the general criteria. What I suggest is that there are also other ways that are much more in tune with the Keynesian paradigm.

To make these points clear, let us start to articulate Keynes's paradigm by making a clear cut distinction between fundamental assumptions or postulates, simplifications and positive heuristics.

\section{Postulates}

Departure from Marshall. Following Davidson, I suggest that in order to restore Keynes's generality claim there is a need to single out the postulates of the GT. Unlike Davidson, I argue that these postulates should be the counterpart of those underlying standard theory (i.e., the axioms of individual rationality, the constructive method and equilibrium), not just those about money or other objects; there is a fundamental behavioural issue to clarify.

My basic claim is that at a fundamental level of Keynes's analysis the "quasi naturalistic" feature of the GT is not the ultimate explanatory factor or postulate. Strictly speaking, it is true that Keynes seems to focus on the abstract nature of economic men in general. In particular, while stressing the role of conventions in shaping money and expectations, he seemed to regard them more as a generic or natural feature of human behaviour (i.e., tendency to be gregarious, copy the others, etc.) than a time contingent one (for example, the conventions that rule in 2020). When discussing specific conventions on financial markets in Chapter 12, he placed them at "lower levels of abstraction", as if the time contingent side of conventions was not part of his "general theory".

However, there is reason to believe that one implication of Keynes's organicist view is that the time contingent aspect of conventions cannot really be isolated from the generic one except for convenience/simplification purposes. In other words, I regard the GT as implying unity or interaction between these two aspects from the start, so that the isolation of the "quasi-naturalistic" aspect is not a postulate but only a useful simplification to build macroeconomics.

On this interpretation, the GT involves a basic change in the very notion of time with respect to the Marshallian tradition. While the latter regards time in an objectivist manner (e.g., the distinction between short and long-run referring to the variability of the capital stock), Keynes seems instead to embrace a subjectivist or “relativistic” view, in line with the philosophical conception of Einstein’s theory. 
To make this point clear, it is useful to start by considering that Keynes broke with Marshall's continuity principle, according to which legal norms, competition and culture (social and ethical norms) co-evolve or change slowly; a view which justified Marshall's belief in "natural laws" which tend to be established in the long-run independently of human will as they reflect the "objective" structure of the "real" economy —including the conditions of production, and the dynamic mechanisms at play such as competition between rational individual agents—as reflected by his reliance upon long-period as theoretical norm.

Indeed, while Marshall tried hard to single out a long period perspective in the midst of "noise" and contingent circumstances which could impair the future, Keynes, especially in the light of the dramatic events of the first half of the 20th century, ended up by holding an opposite view, both in economics and in politics and moral philosophy. As shown by the evolution of his thinking from early writings onwards (see e.g., Raffaelli, 2006), he came to regard instead uncertainty concerning a long-period perspective as "noise", as a factor that tends to exercise paralyzing effects on action: the long-run is not the key reference point for inspiring human action but a vague horizon that threatens reasonable activity today. For this reason, it is right to claim that, in contrast with Marshall, Keynes treated time not as a continuum, but a discontinuous succession of events, a view which accounts for why in the GT he focused on the contingent, on the need to create order in a brief lapse of time. For this reason, he was bound to consider both sides of conventions as the convenient starting point of the analysis.

Key implications of the Keynes/Einstein analogy. As I stressed in previous contributions (see Togati, 1998; 2001), the Keynes/Einstein analogy is very useful to pursue the redefinition of Keynesian paradigm. This is so for at least four reasons.

First of all, the Einsteinian perspective helps us to understand that the GT is a product of Modernism —an extraordinary period which sees many contemporary revolutions and projects of "general theory" in several fields, from art to physics - involving a sharp departure from XIX century approaches (see also Togati, 2012; 2018; 2020).

Like relativity theory in physics and other approaches, Keynes's theory is not aimed at calling into question the whole economics but represents a special theory concerned with the identification of a relatively narrow domain, namely macroeconomic stability. For this reason, it cannot be understood in terms of unifying principles, such as those of value theory, formulated by alternative XIX century approaches.

This point is worth mentioning because in economics, in contrast with other fields, the scene is still occupied by these old paradigms, though in a polished and refined form, and this is nowhere clearer than in macro.

Secondly, the analogy helps us to see that also the GT can be formulated in terms of postulates though it belongs to a very different type of theoretical approach than the standard one. Indeed, the rejection of the axiomatic approach underlying standard theory does not imply the rejection of structure or order as such.

To make this point clear, one should bear in mind that Einstein made a distinction between two types of theories, that between "constructive" theories and "theories-of-principle”, which is also valid for economics. General equilibrium theory is like mechanistic or atomistic theory in physics and other unifying approaches: a constructive theory which starts from the simplest elements (such as individual agents) to account for complex wholes. Keynes instead is very much like Einstein: both start at the opposite, that is from certain systemic properties which cannot be bypassed, such as the constant speed of light for Einstein, and the properties of monetary economy for Keynes. This view, which can be regarded the first postulate of the GT, makes sense of his key insight that rules out "real" benchmarks for good, namely that 
the idea that it is comparatively easy to adapt the hypothetical conclusions of a real wage economy to the real world of monetary economics is a mistake. It is extraordinarily difficult to make the adaption...Accordingly I believe that the next task is to work out in some detail a monetary theory of production. (Keynes, 1937, pp. 409-411)

In particular, what makes a monetary economy a special object that must not reconstructed starting from the hypothetical case of barter or simplified "real" contexts such as the "pure logic of choice" in microeconomic theory is the impossibility of making simultaneous transactions due to the sequential character of decisions (production takes time and must be sold at a later moment, money implies separation of transactions, diversity of agents involved in saving and investment, etc.).

Third, the Keynes/Einstein analogy clarifies the nature of the postulates which underlie Keynes's vision of the economy; in particular, it helps us to stress that they are not limited to money but concern metaphysical considerations about time and scope of science (the nature of scientific knowledge).

It can be argued, for example, that in line with the philosophical conception of Einstein's relativity theory ruling out the concepts of absolute time and space and stressing the interaction between space and matter, for Keynes a monetary economy does not possess an "objective" autonomous dynamics which can be assessed from an absolute standpoint; it not as a self-contained entity (that can be mechanistically decomposed into simple elements) evolving along a predetermined path, but a complex whole which is unable to work spontaneously due to the lack of automatic adjustment mechanisms.

Suffice it to note that the impossibility of simultaneous transactions makes sense of uncertainty and explains why Keynes underlines "subjective" time. By introducing "subjective" dimensions—such as expectations and the feeling of disquietude-in his macroeconomic analysis, Keynes breaks with Marshall's natural laws focusing on "objective", operational time linked to the supply side, i.e., features of production, such as the capital stock. In the GT, disquietude comes into the picture as a collective macro phenomenon hitting the demand side of the economy. ${ }^{4}$

It is not difficult to see that this phenomenon involves an organic or systematic interaction between agents and institutions. Keynes notes for example that it can only be lulled by individuals' possession of money, governed by institutions, such as central banks.

On these grounds, a general "relativistic" point can be made. In Keynes’s perspective, the smooth working of the market or private economy calls for what can be labeled as "premises for markets" or "system of coordinates" - such as a sufficient degree of collective trust and certain institutions (like central banks acting in a fiat money regime) managing it - that are changeable through time and space and thus impair the definition of "natural" laws, such as those underlying standard theory. ${ }^{5}$

It is because of "bad" premises (for example, the system may not produce a sufficient amount of collective trust), rather than relatively small imperfections in the market system itself, that systemic problems such as low effective demand may occur. The internal instability view underlying Keynesian theory amounts to regarding

\footnotetext{
${ }^{4}$ Disquietude comes into the picture as a collective phenomenon in the sense that it implies fragility of the conventional background, not just individual feeling. Central banks reassure markets in two ways. First, they ensure stability of conventional background itself; second, they ensure the stability of money as store of value when conventions break down. They represent an anchor for stability.

${ }^{5}$ This is not to say that the there are no macroeconomic laws tout court and generalization is impossible. In principle, following Einstein, Keynes is about defining laws of a "relativistic" kind in the sense that they do not give rise to regularities but hold only conditionally upon a certain system of coordinates. An instance is the principle of effective demand, that involves different drivers of growth (internal private demand, export-led economies, government expenditure) supported by different set of institutions and conventions.
} 
such bad premises as arising endogenously, that is as products of the normal working of the economy. The key point is that, due to imperfect knowledge, individual agents in order to make decisions and form expectations do not rely on autonomous criteria, such as probabilistic calculations, but on social conventions which are "arbitrary" (for example, they are not uniquely "correct" in the sense of corresponding to a given set of fundamental factors as rational expectations) and "fragile” criteria (in particular, they have a background whose solidity is a function of objective factors including income distribution). ${ }^{6}$

The end of the absolutist conception of time and the fact that the working of the economy cannot be understood without specifying the prevailing system of coordinates or institutional anchors account for another postulate of the GT which captures another of Keynes's key insights: namely the lack of homogeneity of time, according to which only an instantaneous equilibrium picture is fully objective.

In the end, the analogy makes sense of the third postulate of the GT, that is its anti-atomism, which is needed to restore the substantive generality of Keynes's contribution. This point can be made clear by noting that another major link between Keynes and Einstein is that both subscribe to a phenomenological stance, in contrast with essentialism involving a sharp distinction between primary and secondary features.

This stance leads them to recognize the existence of a layered ontology, different layers or objects of reality irreducible to other levels or objects. One can note for example that Einstein recognizes both the role of atoms and the existence of a new entity irreducible to them, such as the field.

On the other hand, based on a phenomenological stance associated with his organicist conception of the economy, Keynes conceives of economic objects as consisting of bundles of strictly interrelated qualities. For this reason, he manages to overcome all the sharp dichotomies or polarities (e.g., micro/macro, monetary/real factors, rationality/irrationality, "self-interest"/"cooperation”, object/subject, exogenous/endogenous variables, and equilibrium or stability/historical processes) — that underlie the standard model, following its essentialist and mechanistic stance. In principle, an intrinsically "relational" or "interactionist" reality should be the regarded as the structural features of capitalism. ${ }^{7}$

A significant implication of this phenomenological stance is that Keynes too can be interpreted as conceiving of aggregates as autonomous features, ultimately irreducible to individual rationality. This is because money and expectations - the very stuff of his aggregates — can be referred to one side of this interactionist: namely, that arising because of the fragility of conventions that depend upon the state of collective confidence whose solidity depends upon objective factors and policy interventions.

\section{Simplifying Assumptions}

However, the usefulness of the Keynes/Einstein analogy is not limited to the understanding of the postulates of the GT. In line with other Modernist revolutions, the Einsteinian revolution also helps us to

\footnotetext{
${ }^{6}$ Keynes emphasized this point already in his 1919 Consequences of the Peace: "The immense accumulations of fixed capital which, to the great benefit of mankind, were built up during the half century before the war, could never have come about in a Society where wealth was divided equitably. This remarkable system depended for its growth on a double bluff or deception. On the one hand the labouring classes accepted from ignorance or powerlessness, or were compelled, persuaded, or cajoled by custom, convention, authority, and the well-established order of Society into accepting, a situation in which they could call their own very little of the cake that they and Nature and the capitalists were co-operating to produce. And, on the other hand, the capitalist classes were allowed to call the best part of the cake theirs and were theoretically free to consume it, on the tacit underlying condition that they consumed very little of it in practice. The duty of 'saving' became nine-tenths of virtue and the growth of the cake the object of true religion" (Keynes, 1919, p. 4).

7 The central role of conventions in the GT is clearly underlined by Keynes; he stressed, for example, that "the rate of interest is a highly conventional, rather than a highly psychological, phenomenon” (Keynes, 1936, p. 203).
} 
understand other key features of Keynes's method which otherwise may appear arbitrary. One distinctive character of such revolutions is that they often turn out to be more one-sided attempts to isolate the "primitives" of various fields, rather than all-encompassing theories; they place more emphasis on innovation or break with tradition than on development of a coherent, full-blown research programme. In my view, this justifies a number of quite drastic heuristic simplifications of complex, organic wholes which are carried out in the GT, often in an implicit manner, to isolate the "primitives" of macroeconomics. Macroeconomics as a technical subject cannot really take shape without them.

In particular, for macroeconomics to exist as an autonomous subject, the organicist vision stressing internal relations between key features of the economy must be necessarily simplified. While according to this vision it is not right to establish ontological priorities or hierarchical orderings between key variables, this is instead what the simplifications actually try to achieve.

This view justifies key features of the GT, such as the conception of aggregates as emergent wholes, the primacy of money and expectations with respect to structural variables, the primacy of "cooperation” with respect to "self-interest", Keynes's focus on equilibrium rather than sequence, the primacy of statics over description of dynamic processes, the emphasis on the "natural” side of conventions and "exogenous" money.

Aggregates as emergent wholes. Keynes’s macro approach depends upon one key simplification with respect to the organicist conception based on a layered ontology (and thus in principle allowing for both the autonomy of aggregates and reference to individuals): namely, the priority of systemic analysis focusing on the interaction between aggregates or markets, rather than individuals.

However, this systemic perspective does not imply the dismissal of individual motives of behaviour, but that these must be analyzed in terms of a "top-down" strategy or "macrofoundations of micro" perspective, according to which the analysis at the individual level is not self-contained but is somehow structured by the whole. This means at least three things.

First of all, individuals are studied in the light of systemic properties, such as conventions. Second, in macro conventions can only be captured in a simplified way, that is as data rather than in terms of process of interaction between agents (as advocated for example by complexity theorists). ${ }^{8}$ For this reason, Keynes's aggregates, which are based on conventional data, can be seen as emergent wholes, just as fields in Einstein's theory of in the Gestalt psychology. ${ }^{9}$ Third, the statistical view of aggregates that is what matters at the aggregate level is not how one representative agent behaves but how individuals are distributed according to some empirical modality which is related to conventional data, such as incomes and wealth distribution affecting the aggregate propensity to consume.

The primacy of money and expectations. Keynes's contribution (i.e., the determination of the level of activity) depends upon introducing one major simplification with respect to the full-blown organic interdependence which could in principle be seen between the key features of the economy. This simplification amounts to establishing a new hierarchical order between such features than the one emphasized by the Marshallian tradition, which accommodated them through the short/long-period distinction.

\footnotetext{
${ }^{8}$ It can be argued that while the complexity approach underlines the primacy of interaction and self-organization features of the economy, Keynes focuses instead on the constraints upon individual behaviour. Individual face a given structure, it is never unconditional behaviour.

9 This fits the "theory of principle" approach and Keynes's emphasis on the role of intuition in picking relevant patterns of behaviour such as psychological law of consumption (see e.g., Backhouse, 2010). In particular, this means that there is no deductive axiomatic foundation: "empirical” features must be brought in as data, from the beginning.
} 
The logic of Keynes's stance is summarized in Chapter 18 of the General Theory, where he makes a distinction between two different sets of "givens", which can be labelled as "primary" and "secondary" variables.

The key propensities to consume, invest, and hold money represent the new permanent or normal drivers, primary or causal factors, of the economy. They crucially depend on expectations; i.e., they are the crucial driver together with money.

Other "structural" givens, such as technology or population or income distribution, appear as secondary. Keynes's view is not that they are irrelevant but that they do not exercise an autonomous causal role; they influence the economy only by affecting the primary givens.

The primacy of "mutual interest". Another key simplification with respect to the organic whole in principle encompassing all dimensions of individual behaviour is that, through the lenses of the GT, the working of the system as a whole appears as the product of a new dimension of individual behaviour alone: namely, agents' cooperation or "mutual interest", which makes sense of concepts like the multiplier and effective demand that involve fundamental complementarity between agents.

The emphasis on "mutual interest" as an autonomous dimension of individual behaviour shows that Keynes is not in tune with the ways of capturing this gap between micro and macro that are present in the literature, such as the fallacies of composition and "the unintended consequences of individual behaviour" (e.g., Rajan, 2010). Suffice it to note a few points.

First, Keynes's macro analysis is not based on (or corresponding to) microeconomic behaviour as normally expressed in standard micro analysis. This is due to the fact that while micro focuses on how firms, for example, pursue self-interest in various market forms, Keynes's macro concepts represent instead the mutual interest between workers and firms. They imply, for example, that an expansion of aggregate demand benefits both, while cutting wages may ultimately impair also firms' interests.

This is another factor that justifies the "macrofoundations for micro" perspective accounting for the autonomy of his aggregate concepts and making redundant detailed descriptions of decision-making processes on individual markets. ${ }^{10}$

The primacy of conventional norms. Keynes's contribution also depends upon another key simplification with respect to the organicist view. While in principle this regards value as being determined by both structural and conventional factors, Keynes's stance amounts to placing almost exclusive emphasis on the latter.

It is true that Keynes emphasizes equilibrium conditions such as that between real wage and marginal productivity of labour or that between the interest rate and marginal efficiency of capital which seem to refer to standard value theory. However, such equalities do not imply the acceptance of this theory. One can note for example that the equality concerning the labour market is only a way of stating the quite uncontroversial principle that prices must cover costs $\mathrm{P}=\mathrm{W} / \mathrm{MPL}$ (where $\mathrm{P}$ is the price level, $\mathrm{W}$ the money wage, and MPL the marginal productivity of labour). This is the core of "natural laws" of economics which we must recognize: Indeed, for firms to exist, it must be true that prices cover costs. This equality implies the acceptance of standard theory when it is accompanied by the proper specification of the nature of the givens involved, and therefore, of causal links.

\footnotetext{
${ }^{10}$ However, it is wrong to believe that in Keynes's analysis self-interest is denied; the key point is that it can only be understood in the light of a higher dimension of agents' behaviour: namely, cooperation. Macro needs to combine both rather than just assume that "order" is the automatic result of self-interest.
} 
Now, Keynes's theory implies causal links that are inconsistent with standard value theory. The latter is based on natural laws - determined on the grounds of factors such as productivity and tastes which are taken as exogenous—as benchmark for actual values.

By placing the emphasis on conventions as primary factors, Keynes instead destroys the "natural" values as benchmark. This is so because in his theory:

(a) there is no exogenous benchmark (i.e., marginal productivity of labour or capital reflecting technology, i.e., fundamentals);

(b) there is no room for "natural" values, such as real interest rate and real wage.

On the one hand, following the theory of principle postulate, for Keynes the only prices that matter are market values and these are defined in money terms (money wages or interest rates).

On the other, conventions set a new kind of "objective” norm, to which actual market values converge. Unlike standard natural benchmarks, these are only "internal” norms, that is a kind of average market prices, determined by considerations of fairness (e.g., labour contracts) or notion of "normal” value (e.g., interest rates or share prices). ${ }^{11}$

Now, since these norms influence expectations, actual prices are not attracted by "fundamental" values determined by standard theory but by these conventional attractors that are relatively stable (e.g., regressive expectations on financial markets, the interest rate going back to normal levels, etc.).

Focus on equilibrium. Another drastic simplification which Keynes makes with respect to his organicist conception - stressing complex dynamic developments in historical time, such as non-ergodic cumulative processes, sequences of events or continuous interaction or feedback between objective data and conventions or preferences and between market prices and the conventional norms-is represented by his focus upon equilibrium states, based on given parameters.

However, this equilibrium approach does not imply the dismissal of concerns about historical time. In contrast with standard theory (and post-Keynesian critics of equilibrium who confuse "vision" with "necessary simplifications"), for Keynes equilibrium is not a postulate but only a technical simplification. There is no doubting that, in principle, he holds to a dynamic "vision", such as the constant flow or sequence of events in historical time. However, the need to construct macroeconomics as an autonomous discipline places a constraint on the way a correct dynamic "analysis" can actually be pursued.

A few points — that are not adequately developed by Keynes—need to be emphasized here.

First, his equilibrium method based on the given money wages "assumption" highlights his alternative approach to stability with respect to orthodoxy. This assumption reflects the fact that flexible prices play no direct equilibrating role in the economy; in particular, the given money wage is only the attractor of a process of retroaction between market wages and the conventional or normal wage occurring in the real-world economy. ${ }^{12}$

Secondly, there is no contrast between "history" and "equilibrium": by focusing on "synchronic" equilibrium, Keynes only states the confines of "objective" economic analysis, that is he believes that his

\footnotetext{
${ }^{11}$ Unlike behaviouralists, the relevant gap for Keynes is not between actual market values and fundamental values: the latter do not simply exist in the GT and it is incorrect to take historical averages of actual prices as reflecting them; such averages are only "normal” rather than "natural” values. The only possible gap for him is that between actual values and normal ones.

${ }^{12}$ It is singled out as parameter because it represents a key systemic constraint that grants the system's temporary equilibrium. Indeed, without it the system would not be in equilibrium, i.e., it would be unstable.
} 
approach is the only "objective” or "determinate” way to accommodate history in macro as general theory, in the same way that Einstein's seemingly static approach is the only objective way to introduce time in an essential manner in physics. $^{13}$ In particular, Keynes's stance implies that historical time should not be dealt with in a "self-contained" fashion on the grounds of formal models as in standard theory. As Keynes makes clear especially in his critique of econometrics, “objective” analysis seeking to account for a real-world economy without relying on a purely deductive, self-contained, approach-which is justified by the internal stability assumption — cannot be pushed further when this assumption is no longer made; the point is that we cannot simply bypass the indeterminacy of agents' mental framework and the subsequent non-homogeneity of economic data through time.

Thirdly, this view does not imply analytical nihilism; in particular, it does not mean that dynamic analysis is impossible; however, it is inevitably either based on particular assumptions — such as those which he relies upon in his analysis of long-run trends in his 1930 work on the Economic Possibilities for Our Grandchildren — or based on "subjective" selection and interpretation of the relevant stylized facts and their impact on drivers. While Keynes seems to suggest that the only thing a theorist can do to face the complexity of actual dynamics is to devise an informal "orderly method" of thinking focusing on temporary equilibrium, ${ }^{14}$ he does not however specify it in full; for example, he does not discuss how primary givens react in the face of changes in objective data.

Focus on the natural side of agents' conventional behaviour. One further major simplification made by Keynes concerns the "psychological” foundations of his theory. It can be argued that his "psychologism” is not a postulate, but only a simplification of the organicist conception of the economy involving the consideration of agents' conventions in their ordinary business life.

In contrast with institutionalists criticizing Keynes for building his “general” theory upon psychological foundations and thus neglecting historical-specificity, one must recall the point I emphasized earlier: namely that, unlike the standard individual preferences that ultimately represent exogenous natural data based on psychology, "ordinary” business conventions have two, strictly interrelated, sides: the first is an invariable, universal, or "natural” feature, underlying behavioural rules, such as people's tendency to believe that tomorrow is like today or copy the others (a tendency which underlies "cooperative” instincts), which is actually rooted in their psychology; the other side, which we could label as "historic-specific", is changeable instead: it refers to, say, what specific conventions were ruling in the US economy in 2007, at the outset of the financial crises. $^{15}$

\footnotetext{
13 This feature of Keynes's work finds a counterpart also in other contemporary Modernist revolutions. Indeed, the attempt to achieve new forms of objectivity through the consideration of time as an essential dimension in a relatively a-historical or “synchronic” picture is a common feature of Picasso's cubist paintings or De Saussure's linguistics.

${ }^{14}$ As Keynes put it: "The object of our analysis is, not to provide a machine, or method of blind manipulation, which will furnish an infallible answer, but to provide ourselves with an organised and orderly method of thinking out particular problems; and, after we have reached a provisional conclusion by isolating the complicating factors one by one, we then have to go back on ourselves and allow, as well as we can, for the probable interactions of the factors amongst themselves. This is the nature of economic thinking. Any other way of applying our formal principles of thought (without which, however, we shall be lost in the wood) will lead us into error. It is a great fault of symbolic pseudo-mathematical methods of formalising a system of economic analysis...that they expressly assume strict independence between the factors involved and lose all their cogency and authority if this hypothesis is disallowed" (Keynes, 1936, p. 297).

${ }^{15}$ One can mention here for example the belief that housing prices could only go up, or a particular model of business in the financial sector, such as the "originate and distribute" model replacing the "originate and hold" model, see e.g., Akerlof and Shiller 2009.
} 
Now, in his book, Keynes simplifies his analysis by regarding conventions more as permanent traits of human nature than as historical features which are subject to change, although he sees an overlap between these two dimensions; for example, he underlines the psychological propensities of "the modern world" which appear as plausible in the light of "facts of experience and a priori knowledge" (Keynes, 1936, pp. 28-29, 89). ${ }^{16}$

Based on this "natural" side of conventional behaviour, Keynes states the principle of effective demand and seeks to establish the generality of his contribution (in the extensive dimension), by accounting for two aspects which were in contrast with the standard theory of his time: namely, both the cyclical nature of capitalism and the permanent possibility that it remains trapped in the state of underemployment equilibrium, i.e., the possibility of multiple equilibria.

Some "natural" properties of economic systems and agents' psychological propensities are such as the following: (a) The multiplier is greater than unity but not very large given normal values of the marginal propensity to consume; (b) a moderate change in the prospective yield of capital-assets or in the rate of interest will not involve an indefinitely great change in the rate of investment; (c) moderate changes in employment are not associated with very great changes in money-wages; (d) fluctuations tend to wear themselves out before proceeding to extremes and eventually to reverse themselves because capital-assets are of various ages, wear out with time, and are not all very long-lived. ${ }^{17}$

Primacy of the trust-restoring function of institutions. In the end, the last key simplification made in the GT with respect to the organicist conception of the economic process concerns the role of policy. In particular, it can be argued that following this conception, in order to grant macroeconomic stability, institutions should both try to validate or support the workings of a free market economy and try to amend its failures.

One key aspect of the economic process for which this claim is true is trust. It can be argued for example that trust is both endogenous to the operations of a market economy (the development of exchanges guided by flexible prices brings about the possibility of further expansion due to the fact that people learn to trust each other) and exogenous (a market economy may not be able to produce autonomously a sufficient amount of trust; there may be a lack of fiduciary prerequisites which must be remedied by external interventions).

Now the policy prescriptions that underlie the two basic macro paradigms are justified by the way they simplify this picture. While standard theory ultimately emphasizes the endogenous nature of trust so that macro policy must avoid impairing it by sticking to some tight rules as much as possible (e.g., balanced budget and inflation targeting), Keynes's simplification instead is to suppose that collective trust is exogenous; it acts as an exogenous constraint. Indeed, as already noted, the real problem behind the lack of aggregate demand is not the working of individual markets for goods or labour but a lack of fiduciary prerequisites. In particular, ordinary conventions may break down; people refrain from spending and seek refuge in the possession of money due the fragility of the conventional background, which market incentives are unable to cure.

In this light, the primary task of stabilization policy is to restore "collective trust", a task which can be carried out in several ways. The first is to preserve the ability of money to lull agents' anxiety when "normal"

\footnotetext{
${ }^{16}$ Keynes considers, for example, "what hypothetical psychological propensities would lead to a stable system; and, then, whether these propensities can be plausibly ascribed, on our general knowledge of contemporary human nature, to the world in which we live” (Keynes, 1936, p. 250; my emphasis).

${ }^{17}$ Keynes continues as follows "so that if the rate of investment falls below a certain minimum level, it is merely a question of time (failing large fluctuations in other factors) before the marginal efficiency of capital rises sufficiently to bring about a recovery of investment above this minimum” (ibid.).
} 
conventions break down (clearly, holding money causes a lack of aggregate demand problem, but rejection of the money standard itself makes it certainly harder). In a fiat money regime, where there are no longer "objective" anchors such as gold, this means reinforcing the credibility of the central bank to act as defender of the value of money or "lender of last resort". In this sense, the money supply is "exogenous". This is a necessary implication of Keynes's acceptance of the Chartalist view of money, according to which state intervention is needed to support the acceptance of the legal tender.

\section{What Positive Heuristics?}

The generalization of the GT in policy terms. In the light of the distinction between his basic postulates and simplifying assumptions which has been carried out in this paper, some concluding remarks can be devoted on how to develop the Keynesian research programme.

In principle, Keynesian theory can be seen as treating as a problem what standard theory takes for granted, namely macro stability. However, despite his refusal of the stability assumption-that is the non-homogeneity of time undermines the standard methods such as econometrics and self-contained models, which rely on stable parameters-Keynes failed to discuss the evolution of the key parameters underlying aggregate demand.

He seemed to be unaware that his simplifying assumptions are only heuristic ones that make sense in an instantaneous equilibrium perspective and thus should be replaced by specific assumptions concerning the evolution of the givens. ${ }^{18}$ This is the task of the "generalization of the GT" in dynamic terms, which is needed in order to establish its generality in policy terms, a dimension of generality calling for consistency between short and long period analysis.

This goal can be obtained by providing a discussion of evolution of drivers in historical time context. This is a "relativistic" turn, which means considering the historic-contingent side of conventions and their influence upon agents' propensities and collective trust. The consideration of the historic-specific aspect of conventions also invites economists to "operationalize" the principle of effective demand by seeking to identify which components of aggregate demand matter in different circumstances and institutional settings. It can be argued for example that different engines of growth are consistent with the general principle. One thing is to rely mainly on exports as Germany or China do, and another is to rely on internal demand as the US, etc. They imply a different role of public expenditure and the establishment of different types of conventions.

What formal models? In principle, there is no doubting that the development of stability analysis along these lines, i.e., in terms of changes in endogenous propensities and collective trust, requires some kind of "narrative" approach. However, the question is not to drop formal models per se-given the role of heuristic simplifications in Keynes's approach, the latter is likely to be consistent with some kind of formalization at least as a pedagogical tool—but to ensure that the models used are consistent with the overall paradigm.

I suggest that also when using more or less standard macro models one can tell the difference that the Keynesian perspective presented here makes with respect to standard one. For example, the endogenous perspective put forward here implies certain shifts and shapes of the curves in the AD/AS model, because it denies the tendency towards full equilibrium (long-period equilibrum is no longer an attractor). Suffice it to note that while standard macro theory stresses—in view of its internal stability assumption—-that falling wages

\footnotetext{
${ }^{18}$ In principle, there are two kinds of specific assumptions concerning the evolution of parameters: the first is the a priori type based on insights concerning human nature (this is Keynes’s method in his 1930 Grandchildren piece); the second, is the one that relies on evolution in actual contexts.
} 
and prices push the curves towards the centre of gravity represented by full employment income, our Keynesian approach stresses instead that the two curves do not shift in this manner because there is no centre of gravity, since collective trust is further impaired by deflation (the endogenous perspective matters).

\section{Conclusion}

The main conclusion of this paper is that in order to restore the generality of the GT one should reassess Keynes's contribution in a very broad perspective.

In particular, this paper has tried to understand the limitations of Keynes's own contribution. Its main conclusion is that Keynes failed to consider all the dimension of the generality issue because he had to face the Marshallian tradition in the shape of Pigou's classical model, rather than a full general equilibrium paradigm as we do now. Keynes therefore could not see the need to build a full-blown paradigm (which would have required making a clear-cut distinction between postulates, simplifying assumption and heuristics) to challenge the contemporary orthodox thinking.

Another conclusion that follows from the paper is that post-Keynesians have been relatively silent on the generality issue and quite unable to remedy Keynes's limitations by building the needed alternative paradigm.

In the end, this paper has tried to show that one promising way to perform this task is to pursue the Keynes/Einstein analogy which has been little explored in the social sciences.

\section{References}

Akerlof, G. A., \& Shiller, R. J. (2009). Animal spirits. Princeton: Princeton University Press.

Blanchard, O. (2000). What do we know about macroeconomics that Fisher and Wicksell did not? Quarterly Journal of Economics, 115(4), 1375-1409.

Davidson, P. (2003). Is "mathematical science" an oxymoron when used to describe economics? Journal of Post-Keynesian Economics, 25(4), 527-545.

Dow, S. (2013). Methodology and post-Keynesian economics. In G. C. Harcourt and P. Kriesler (Eds.), The Oxford handbook of post-Keynesian economics (pp.80-99). Oxford: Oxford University Press.

Gerrard, B. (1995). Keynes, the Keynesians and the classics: A suggested interpretation. Economic Journal, 105(429), $445-458$.

Greenspan, A. (2008). We will never have a perfect model of risk. Financial Times, 17 March, 2008.

Hodgson, G. (2001). How economics forgot history. The problem of historical specificity in social science. London and New York: Routledge.

Keynes, J. M. (1919). The economic consequences of the peace. Collected writings, Vol. II. London: Macmillan.

Keynes, J. M. (1936). The general theory of employment, interest and money. Collected writings, Vol. VII. London: Macmillan.

Keynes, J. M. (1937). The general theory of employment. Quarterly Journal of Economics, 51(2), 209-223.

Keynes, J. M. (1973). The general theory and after. Part I: Preparation. Collected writings, Vol. XIII. London: Macmillan.

Leontief, W. (1937). Implicit theorizing: A methodological criticism of the Neo-Cambridge School. Quarterly Journal of Economics, 51(2), 337-351.

Leontief, W. (1947). Postulates: Keynes's general theory and the classicists. In S. E. Harris (Ed.), The new economics (pp. 232-242). New York: Alfred A. Knopf.

Raffaelli, T. (2006). Keynes and philosophers. In R. E. Backhouse and B. W. Bateman (Eds.), The Cambridge companion to Keynes (pp. 160-179). Cambridge: Cambridge University Press.

Rajan, R. (2010). Fault lines: How hidden fractures still threaten the world economy. Princeton: Princeton University Press.

Togati, T. D. (1998). Keynes and the neoclassical synthesis. Einsteinian versus Newtonian macroeconomics. London: Routledge.

Togati, T. D. (2001). Keynes as the Einstein of economic theory. History of Political Economy, 33(1), 117-138.

Togati, T. D. (2012). The crisis in macro and the limitations of the economics of Keynes - or why the master will not return unless his general theory is dressed up in neo-modern clothes. In J. Jespersen and M. O. Madsen (Eds.), Keynes's general theory for today (pp. 40-59). Cheltenham: Edward Elgar. 
Togati, T. D. (2018). What future for "macroeconomics after Keynes”? A road map to restore the generality of the general theory. In S. Dow, J. Jespersen, and G. Tily (Eds.), The general theory and Keynes for the 21st century (pp. 57-69). Cheltenham: Elgar.

Togati, T. D. (2019). How can we restore the generality of the general theory? Making Keynes's "implicit theorizing” explicit. Cambridge Journal of Economics, 43, 1397-1415.

Togati, T. D. (2020). General theorising and historical specificity in the "Keynes vs. the classics" dispute. Eastern Economic Journal, forthcoming. Retrieved from https://doi.org/10.1057/s41302-020-00177-1 